SHORT REPORT

\title{
Sickness absence as a risk marker of future disability pension: the 10-town study
}

\author{
Mika Kivimäki, Pauli Forma, Juhani Wikström, Tuomo Halmeenmäki, Jaana Pentti, Marko \\ Elovainio, Jussi Vahtera
}

J Epidemiol Community Health 2004;58:710-711. doi: 10.1136/jech.2003.015842

$\mathrm{S}$ ickness absence is increasingly recognised as a measure of ill health. Studies have examined associations between absence, morbidity, and mortality, ${ }^{1-3}$ but less is known about the status of sickness absence as a risk marker for future disability retirement, ${ }^{4-6}$ the focus of this study.

\section{METHODS}

Participants selected from the on-going Finnish 10-town study ${ }^{4}$ comprised all 46569 full time municipal employees who had a job contract lasting a minimum of three full consecutive years between 1 January 1990 and 31 December 2000, and were below 55 at the end of the follow up, the age before which medical causes exclusively determine granting of disability pension for municipal employees in Finland. We obtained sickness absence records from employers' registers for a fixed three year period of employment (the length of exposure assessment period was the same for all participants). The start of this period varied between 1 January 1990 and 1 January 1998 depending on the date when the job contract began. For those employees who had a job contract of more than three years, absences for the first three years were included in the analysis.

We determined disability retirements from the end of the assessment period for sickness absence until the end of 2001 (mean follow up 5.1 years) using data obtained from the Finnish Local Government Pensions Institution and the State Treasury-that is, institutions granting all the pensions to Finnish public sector employees. We analysed all cause disability pensions and pensions attributable to psychiatric diseases (International Classification of Diseases, ICD9 290319; ICD10 F00-F99) and musculoskeletal diseases (ICD9 710-739; ICD10 M00-M99). Death certificates used to determine the end of follow up for participants who died

Table 1 Associations between sickness absence and later disability pension granted below age 55 among municipal employees, 10-town study, Finland

\begin{tabular}{|c|c|c|c|c|}
\hline \multirow[b]{2}{*}{ Sex and measure of sickness absence ${ }^{*}$} & \multirow{2}{*}{$\begin{array}{l}\text { Number of participants } \\
\text { (number of disability } \\
\text { pensions) }\end{array}$} & \multicolumn{3}{|c|}{ Hazard ratio (95\% confidence intervals) } \\
\hline & & Model It & Model $2 \ddagger$ & Model $3 \S$ \\
\hline \multicolumn{5}{|l|}{ Men } \\
\hline \multicolumn{5}{|l|}{ Short ( $1-3$ days) spells per year } \\
\hline 0 & $3599(65)$ & 1.0 & 1.0 & 1.0 \\
\hline$>0-2$ & 7994 (249) & $1.9(1.4$ to 2.5 & $1.6(1.1$ to 2.3$)$ & $1.0(0.7$ to 1.6$)$ \\
\hline$>2$ & 2003 (114) & $4.1(2.9$ to 5.6$)$ & $3.8(2.6$ to 5.7$)$ & $1.5(0.9$ to 2.4$)$ \\
\hline \multicolumn{5}{|l|}{ Long (>3 days) spells per year } \\
\hline 0 & $5582(46)$ & 1.0 & 1.0 & 1.0 \\
\hline$>0-1$ & 7109 (251) & $2.8(2.0$ to 4.0$)$ & $2.4(1.6$ to 3.6$)$ & $1.9(1.2$ to 3.1$)$ \\
\hline$>1$ & 905 (131) & $11.8(8.4$ to 16.6$)$ & $7.3(4.9$ to 10.7$)$ & $3.5(2.0$ to 6.1$)$ \\
\hline \multicolumn{5}{|l|}{ Total absence days per year } \\
\hline 0 & $2272(16)$ & 1.0 & 1.0 & 1.0 \\
\hline$>0-15$ & $8607(149)$ & $2.7(1.6$ to 4.6$)$ & $2.5(1.4$ to 4.4$)$ & $1.3(0.6$ to 2.8$)$ \\
\hline$>15$ & $2717(263)$ & 15.4 (9.0 to 26.2$)$ & $8.8(4.8$ to 15.8$)$ & $2.4(1.0$ to 5.7$)$ \\
\hline \multicolumn{5}{|l|}{ Long spells attributable to injury per year } \\
\hline 0 & 11978 (327) & 1.0 & 1.0 & 1.0 \\
\hline$>0$ & 1361 (92) & $2.2(1.7$ to 2.8$)$ & $2.5(1.8$ to 3.4$)$ & $1.4(1.0$ to 1.9$)$ \\
\hline \multicolumn{5}{|l|}{ Women } \\
\hline \multicolumn{5}{|l|}{ Short ( $1-3$ days) spells per year } \\
\hline 0 & $4285(70)$ & 1.0 & 1.0 & 1.0 \\
\hline$>0-2$ & 19129 (494) & $1.7(1.3$ to 2.2$)$ & $1.6(1.2$ to 2.2$)$ & $1.0(0.7$ to 1.4$)$ \\
\hline$>2$ & $9559(422)$ & 3.5 (2.7 to 4.5$)$ & $3.2(2.4$ to 4.3$)$ & $1.1(0.8$ to 1.6$)$ \\
\hline \multicolumn{5}{|l|}{ Long ( $>3$ days) spells per year } \\
\hline 0 & $10400(64)$ & 1.0 & 1.0 & 1.0 \\
\hline$>0-1$ & 19415 (521) & $2.9(2.2$ to 3.9$)$ & $2.9(2.1$ to 3.9$)$ & $2.2(1.5$ to 3.0$)$ \\
\hline$>1$ & $3158(401)$ & $12.1(9.3$ to 15.6$)$ & $9.6(7.2$ to 12.7$)$ & $4.2(2.9$ to 6.1$)$ \\
\hline \multicolumn{5}{|l|}{ Total number of absence days per year } \\
\hline 0 & 2475 (14) & 1.0 & 1.0 & 1.0 \\
\hline$>0-15$ & $21992(276)$ & $2.5(1.5$ to 4.3$)$ & $3.0(1.6$ to 5.7$)$ & 1.5 (0.7 to 3.2$)$ \\
\hline$>15$ & $8506(696)$ & 15.1 (8.8 to 25.6$)$ & $13.6(7.3$ to 25.7$)$ & $3.4(1.5$ to 7.6$)$ \\
\hline \multicolumn{5}{|l|}{ Long spells attributable to injury per year } \\
\hline 0 & $30363(850)$ & 1.0 & 1.0 & 1.0 \\
\hline$>0$ & 1915 (124) & $2.0(1.6$ to 2.4$)$ & $1.9(1.5$ to 2.4$)$ & $1.1(0.8$ to 1.3$)$ \\
\hline
\end{tabular}




\section{Key points}

- The rate of medically certified absences and the total number of absence days per year have high predictive validity for future disability pension, in particular, due to musculoskeletal disorders.

- Short term absences predict disability pension only to the extent they are associated with other indices of sickness absence.

were obtained from the national mortality register kept by Statistics Finland (official Finnish government statistics).

\section{RESULTS}

Table 1 shows the results of Cox proportional hazard models regarding the associations between sickness absence and later disability pension. After adjustment for demographic characteristics and town, high rates in all measures of sickness absence were strongly predictive of subsequent retirement (model 1). In the sample, 775 permanent and 639 fixed term disability pensions were granted. Sickness absence predicted equally well both categories of disability pension.

To eliminate confounding attributable to long sick leaves immediately before granting disability pension, we started the follow up two years after the end of the assessment period for sickness absence and excluded those 5454 employees who reached the age of 55 , died or retired in the two years after the assessment of sickness absence (model 2, mean follow up 3.6 years). This attenuated most of the associations. To compare the relative predictive validity between different indicators of sickness absence, we simultaneously entered all the measures of sickness absence into the model (model 3). Long absence spells and total number of sick days remained the strongest independent predictors of later disability pension.

Men and women were combined in the analysis of cause specific disability retirements. Long absence spells and total number of sick days were the strongest predictors of disability pension attributable to psychiatric and musculoskeletal disorders, the two leading causes: after adjustment for demographics and town, hazard ratio for high rate of long spells was 15.1 (95\% confidence intervals 10.6 to 21.4 ) for psychiatric disability pension and 19.4 (12.2 to 30.6) for musculoskeletal disability pension. For total number of sick days, the corresponding hazard ratios were 14.5 (8.2 to 25.5) and 24.9 ( 10.2 to 60.5$)$, respectively.

\section{DISCUSSION}

This is apparently the first prospective cohort study to systematically compare the predictive validity between common indicators of sickness absence in relation to all cause and cause specific disability retirement. We found rate of long term certified absence spells and total number of annual sick days to be strongly predictive of becoming a disability pensioner under the age 55, particularly due to musculoskeletal disorders. This implies that levels of these sickness absence measures are risk markers for future rates of disability pensions in the labour force. The predictive validity of short absence spells and absence from injury was lower and was largely accounted for by their association with long absence spells and total number of absence days.

Our findings strengthen evidence on the status of sickness absence as a measure of health differentials in working population. Although the associations between sickness absence and disability pension were stronger than those found between sickness absence and mortality, ${ }^{2}{ }^{3}$ all the
Policy implications

- Sickness absence records may provide a useful risk marker for predicting future disability retirements.

- There seems to be a reasonable time lag between the sickness absence and disability pension during which the employer, management, and occupational health professionals can intervene and potentially prevent early disability from occurring.

results consistently underline the importance of focusing on long term certified absences and total sick days rather than other indicators of sickness absence. For practical implications, an important finding seems to be the reasonable time lag between the sickness absence and disability pension during which the employer, management, and occupational health professionals can intervene and potentially prevent early disability from occurring.

\section{ACKNOWLEDGEMENTS}

We thank Dr Jane E Ferrie for her comments on an earlier draft of this paper.

\section{CONTRIBUTORS}

All authors participated in designing the hypothesis, interpreting the results and writing the paper. MK, the principal investigator, is guarantor of the paper. JV, the director of the 10-town study, and JP analysed the data.

\section{Authors' affiliations}

M Kivimäki, Department of Psychology, University of Helsinki, Finland P Forma, T Halmeenmäki, The Local Government Pensions Institution, Helsinki, Finland

J Wikström, State Treasury, Helsinki, Finland

J Pentti, J Vahtera, Finnish Institute of Occupational Health, Helsinki, Finland

M Elovainio, National Research and Development Centre for Health and Welfare, Helsinki, Finland

Funding: this study was supported by the Academy of Finland (projects 105195 and 77560 ), the Finnish Work Environment Foundation (project 101190) and the participating towns.

Conflicts of interest: none declared.

Ethical approval: the ethics committee of the Finnish Institute of Occupational Health have approved the 10-town study.

Correspondence to: Professor M Kivimäki, Finnish Institute of Occupational Health, Topeliuksenkatu 41 aA, FIN-00250 Helsinki, Finland; mika.kivimaki@Hl.fi

Accepted for publication 29 October 2003

\section{REFERENCES}

1 Marmot M, Feeney A, Shipley $M$, et al. Sickness absence as a measure of health status and functioning: from the UK Whitehall II study. J Epidemiol Community Health 1995;49:124-30.

2 Kivimäki M, Head J, Ferrie JE, et al. Sickness absence as a global measure of health: evidence from mortality in the Whitehall II prospective cohort study. BMJ 2003;327:364-8

3 Vahtera J, Pentti J, Kivimäki M. Sickness absence as a predictor of mortality among male and female employees. J Epidemiol Community Health 2004;58:321-6.

4 Biering-Sorensen F, Lund J, Hoydalsmo OJ, et al. Risk indicators of disability pension. A 15 year follow-up study. Dan Med Bull 1999;46:258-62.

5 Borg K, Hensing G, Alexanderson K. Predictive factors for disability pensionan 11 -year follow up of young persons on sick leave due to neck, shoulder, or back diagnoses. Scand J Public Health 2001;29:104-12.

6 Salonen $\mathrm{P}$, Arola $\mathrm{H}, \mathrm{Nygard} \mathrm{CH}$, et al. Factors associated with premature departure from working life among ageing food industry employees. Occup Med 2003;53:65-8. 